\title{
CLINICAL PATTERN AND RISK FACTORS OF RESPIRATORY ALLERGIES DUE TO AMBROSIA (RAGWEED) POLLEN: EXPERIENCE OF ONE ALLERGY CENTER FROM BUCHAREST
}

\author{
Polliana M. LERU ${ }^{1,2} \bowtie$, Vlad F. ANTON ${ }^{2}$ \\ 1 „Carol Davila University of Medicine and Pharmacy, Bucharest, Romania \\ ${ }^{2}$ Colentina Clinical Hospital, Bucharest, Romania
}

Received 15 Oct 2019, Accepted 13 Nov 2019

https://doi.org/10.31688/ABMU.2019.54.4.13

\begin{abstract}
Introduction. Ambrosia artemisiifolia (common ragweed) is an invasive weed with capacity for rapid growth in many disturbed environments, whose highly allergenic pollen appears to be a significant public health problem. Ambrosia is now recognized to have a significant contribution to increased risk of air pollution and of respiratory diseases in urban environment.
\end{abstract}

The aim of our study was to evaluate clinical aspects and risk factors of patients diagnosed with respiratory allergies due to Ambrosia pollen, addressed to our Allergy center from Bucharest, Romania.

Material and methods. We performed a retrospective study of patients confirmed with allergy to Ambrosia pollen for a period of 33 months, between January 2017 - October 2019.

Results. From a total number of 760 patients addressed for respiratory symptoms, 184 patients (24.21\%) were diagnosed with clinical allergy due to Ambrosia pollen, based on clinical picture and specific serologic or skin tests. The clinical forms were seasonal

\section{Résumé}

Modèle clinique et facteurs de risque des allergies respiratoires dues au pollen de l'Ambroisie: expérience d'un Centre d'Allergologie de Bucarest

Introduction. Ambrosia artemisiifolia est une plante envahissante qui peut se développer rapidement dans de nombreux environnements perturbés et dont le pollen hautement allergène semble constituer un problème de santé publique majeur. Il est maintenant reconnu que l'ambroisie contribue de manière significative à l'augmentation du risque de pollution de l'air et de maladies respiratoires en milieu urbain.

Le but de notre étude était d'évaluer les aspects cliniques et les facteurs de risque des patients chez qui on a diagnostiqué des allergies respiratoires à cause du pollen d'Ambroisie et qui ont été adressés à notre centre d'allergologie de Bucarest, Roumanie.

Matériel et méthode. Nous avons réalisé une étude rétrospective basée sur les dossiers des patients allergiques au pollen d'Ambroisie confirmés pendant une période de 33 mois, de Janvier 2017 à Octobre 2019. 
allergic rhinitis in 42 cases, seasonal rhino-conjunctivitis in 65 cases, rhino-sinusitis in 49 cases and rhinitis complicated with allergic asthma in 28 cases. Moderate and severe clinical forms, according to symptoms scores, were recorded in 147 cases (79.89\%). History of atopy was found in 22 patients (11.95\%). Almost all patients have admitted environmental exposure to the plant Ambrosia, either at home or at the working place. The mean duration from symptoms onset until presentation to allergist consultation was 3.2 years.

Conclusions. Our data confirm the serious and increasing burden of respiratory allergies due to Ambrosia pollen in clinical practice.

Keywords: Ambrosia pollen, clinical pattern, respiratory allergies, risk factors.

\section{INTRODUCTION}

Respiratory allergies are chronic diseases with increasing prevalence and severity worldwide, considered an important part of the global allergy epidemic during the last decades ${ }^{1}$. Allergies due to pollen of allergenic plants represent a global health problem in Europe and other parts of the world, estimated to affect almost half of the general population, with significant individual and socio-economic consequenc$\mathrm{es}^{2}$. Ambrosia artemisiifolia (common ragweed) is an invasive weed with rapid spread in many regions of the world, representing an important problem for the environment and for public health, due to its highly allergenic pollen. Originated from North America, where it is considered one of the strongest sensitizing pollen since the end of nineteenth century, Ambrosia is now intensively studied and serves as a model of worldwide allergen expansion and of future possible impact of major climate change ${ }^{3}$. The first medical description of ragweed pollen allergy as „autumnal catarrh" was published by the American medical doctor Morrill Wyman in $1875^{4}$. Ambrosia is responsible for significant health and economic impact in the most infested areas from Europe, such as France, Italy, Austria, Hungary and neighboring countries, including Romania ${ }^{5}$. It is considered that one in five European people suffers from respiratory allergy due to Ambrosia pollen and this is estimated to become a major health problem across Europe ${ }^{6}$. Data from
Résultats. Sur un total de 760 patients traités pour des symptômes respiratoires, 184 patients $(24,21 \%)$ ont été diagnostiqués avec allergie clinique à cause du pollen d'Ambroisie, basée sur le tableau clinique et les tests sérologiques ou cutanés spécifiques. Les formes cliniques étaient la rhinite allergique saisonnière dans 42 cas, la rhino-conjonctivite saisonnière dans 65 cas, la rhino-sinusite dans 49 cas et la rhinite compliquée d'asthme allergique dans 28 cas.

Des formes cliniques modérées et sévères, selon les scores de symptômes, ont été enregistrées dans 147 cas (79,89\%). Des antécédents d'atopie ont été trouvés chez 22 patients (11,95\%). Presque tous les patients ont admis une exposition environnementale à l'Ambroisie, soit à la maison soit au lieu de travail. La durée moyenne depuis l'apparition des symptômes jusqu'à la présentation à la consultation d'allergologie était de 3,2 ans.

Conclusions. Nos données confirment l'importance et la sévérité des allergies respiratoires à cause du pollen d'Ambroisie dans la pratique clinique.

Mots-clés: allergies respiratoires, caractéristiques cliniques, facteurs de risque, pollen d'Ambroisie.

the European Aeroallergen Network (EAN) confirm the continuous increase of infested areas and of the atmospheric ragweed pollen load, with an estimated four times increase of Ambrosia pollen concentration until 20507. Despite generally occurring in dry and abandoned fields, along railways and roadsides, Ambrosia is now recognized as part of urban vegetation in some big cities, contributing to increased risk of air pollution and of respiratory diseases ${ }^{8}$. It was proved that elevated $\mathrm{CO} 2$ environments can stimulate ragweed pollen production, this finding anticipating increase ragweed pollen load as a result of climate change and global warming. Some authors attributed the expansion of ragweed in both the United States and Europe to increasing deforestation and economic development ${ }^{10}$. Actual trends of ragweed expansion in Europe include geographical expansion of the infested areas to the Northern and Eastern Europe due to climate change and the ability of ragweed pollen to be transported at long distances, situated at hundreds of kilometers from the source areas ${ }^{11}$. Romania is included among the most Ambrosia infested countries in Europe and this plant is now considered a real danger for human health and for the environment, rising a major public concern ${ }^{12}$. Recent studies confirm spatial and temporal variations in airborne Ambrosia pollen between European countries and the importance of continuous pollen monitoring in all countries, as well as correlations with health data from allergists regarding affected people ${ }^{13}$. 
In 2014 we started pollen monitoring for the first time in Bucharest at the Allergology Laboratory from Colentina Clinical Hospital, located close to Bucharest city center, based on collaboration with European specialists and institutions. Our data showed significant amount of Ambrosia pollen in Bucharest, with maximum values during early September, when the plant reaches the peak of flourishing and releases high amount of pollen in the atmosphere ${ }^{14}$. Since 2010 we also performed medical education and public activities dedicated to prevention and early diagnosis of allergies due to Ambrosia pollen and we encouraged allergic patients to associate and be involved in coordinated media campaign ${ }^{15}$.

The obJective OF OUR STUDY was to evaluate the clinical aspects and risk factors of patients addressed to our Allergy center from Bucharest, Romania, who were diagnosed with respiratory allergies due to Ambrosia pollen during a period of 33 months, between January 2017- October 2019.

\section{Material AND Method}

We performed a retrospective study of hospital data of patients addressed to the Allergy department of the Colentina Clinical Hospital, Bucharest, Romania, who were confirmed with clinical allergy to Ambrosia pollen, during a 33 months period, between January 2017 - October 2019. We recorded: patient general data, including living and working place, history of atopy, respiratory symptoms and clinical diagnosis, seasonal or persistent pattern, symptoms severity and duration from onset until first presentation to allergist consultation. Clinical diagnosis of rhinitis, conjunctivitis and asthma and the severity of symptoms were assessed using international updated guidelines: Allergic Rhinitis and its Impact on Asthma (ARIA) guidelines - 2016 revision $^{16}$ and Global Initiative for Asthma. Global Strategy for Asthma Management and Prevention (GINA), $2019^{17}$. A total nasal symptom score (TSS) $<6$ indicated mild rhinitis, TSS $>6$ indicated moderate-severe rhinitis. Based on TSS score we identified 37 mild cases and 147 moderate-severe cases. Diagnosis of seasonal allergic asthma was considered based on variable respiratory symptoms: cough, dyspnea, wheezing, preceded by nasal and/or ocular symptoms, with or without clinical and functional signs of bronchial obstruction. Due to acute symptoms, sensitization to Ambrosia pollen was confirmed based on evidence of serum specific IgE in most of the cases, using the multiple allergens Imunoblot method.

\section{Results}

From the total number of 760 patients with respiratory symptoms, addressed for allergist consultation to our hospital-based Allergy center, during a period of 33 months, we found that 184 patients (24.21\%) were diagnosed with clinical allergy due to Ambrosia pollen. The mean age of the studied group was 35,5 years, with almost equal gender distribution. Regarding patients living place, 90 patients lived in city area of Bucharest, 49 patients lived in the neighboring Ilfov County and 45 patients lived in other places at about $100 \mathrm{~km}$ distance from the city center. In three patients who were working in a railway station with a lot of Ambrosia plant on site we could identify occupational exposure and we referred them to working medicine specialist. Most of the patients $(84.7 \%)$ came to the hospital during the pollen season (August-September), when they had acute respiratory, nasal or ocular symptoms. History of personal and/or familial atopy was found in 22 patients (11.95\%). Almost all patients have admitted environmental exposure to the plant Ambrosia during many years, either at home or at the working place (Table 1).

The allergist assessment included: detailed medical history, evaluation of specific nasal or ocular symptoms (sneezing, rhinorrhea, nasal congestion, nasal and ocular itching) evaluated on a scale from 0 (lack of symptoms) to 3 (severe symptoms),

Table 1. General characteristics of the study group

\begin{tabular}{|c|c|c|}
\hline Age & Mean (range) & 35.5 years $(8-78)$ \\
\hline \multirow{2}{*}{ Gender } & $\mathrm{M}$ & 94 pts $(51.08 \%)$ \\
\hline & $\mathrm{F}$ & 90 pts $(48.92 \%)$ \\
\hline \multirow{3}{*}{ Living area } & Bucharest & 90 pts $(48.92 \%)$ \\
\hline & Ilfov county & 49 pts $(26.63 \%)$ \\
\hline & Within $100 \mathrm{~km}$ region & 45 pts $(26.45 \%)$ \\
\hline \multirow{2}{*}{ Time of medical presentation } & Pollen season (August-September) & 156 pts $(84.78 \%)$ \\
\hline & Rest of the year & 28 pts $(15.22 \%)$ \\
\hline History of atopy & Personal and/or familial & 22 pts $(11.95 \%)$ \\
\hline
\end{tabular}




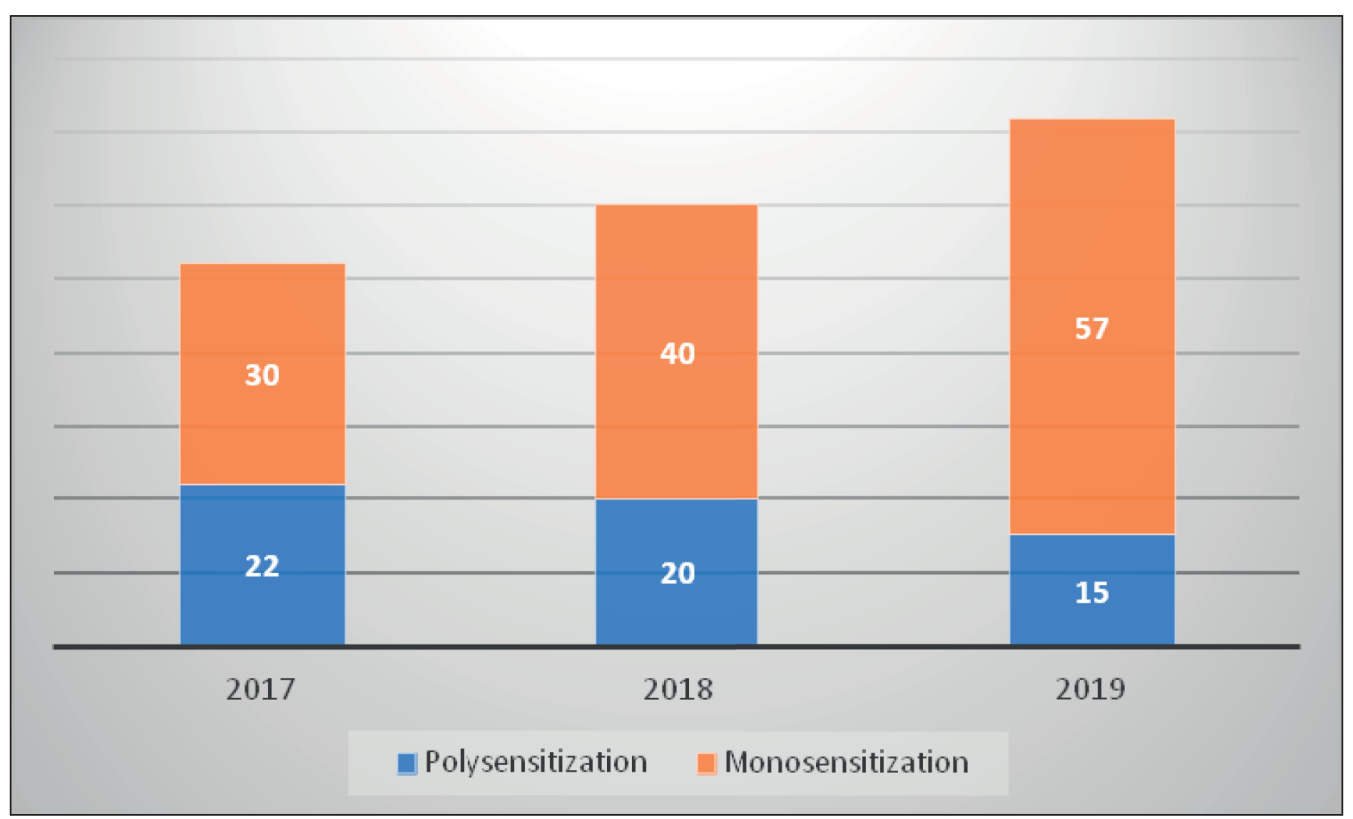

Figure 1. Number of new cases /year and allergic sensitization

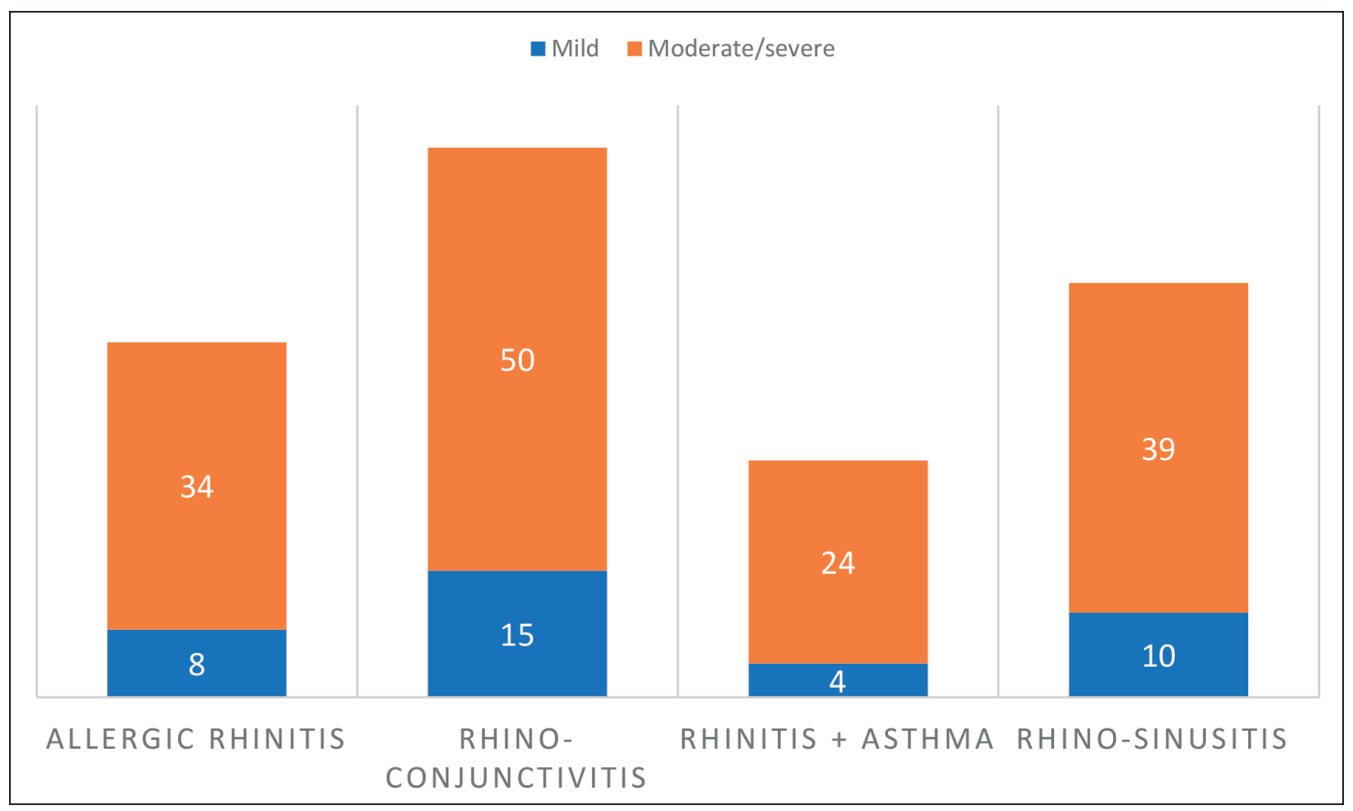

Figure 2. Clinical diagnosis and severity

and determination of serum specific Ig E for respiratory allergens (multiple allergens Imunoblot method, EuroBlotOne). Based on symptoms scores, the total symptoms score (TSS) was calculated according to ARIA Guidelines ${ }^{16}$. A total number of 52 new cases were diagnosed in 2017, 60 new cases in 2018 and 72 new cases in 2019. Based on serological or skin tests to aeroallergens, we identified 127 patients with monosensitization to Ambrosia pollen and 57 patients with concomitant sensitization to one or more inhaled allergens, including house dust mites, grass pollen, cat and dog (Figure 1).
The clinical forms were seasonal allergic rhinitis in 42 cases, seasonal rhino-conjunctivitis in 65 cases, rhino-sinusitis in 49 cases and rhinitis complicated with allergic asthma in 28 cases. Clinical pattern of seasonal respiratory allergy was found in 124 cases (65.21\%) and persistent clinical pattern with seasonal aggravation in 60 patients $(34.79 \%)$. Moderate and severe clinical forms, according to symptoms scores, were recorded in 147 cases (79.89\%) (Figure 2).

Only 37 patients $(20.10 \%)$ asked medical assistance within the first month after onset of symptoms and the mean duration from symptoms onset until 


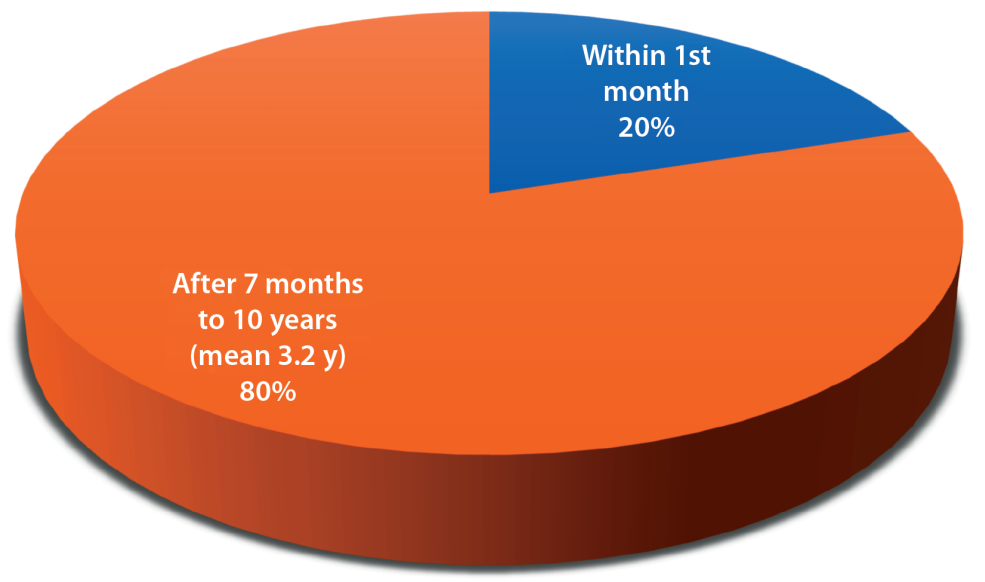

Figure 3. Time from symptoms onset until medical presentation

presentation to allergologist consultation was 3.2 years (between 7 month and 10 years) (Figure 3).

\section{Discussion}

Recent data from the literature showed a continuous increase of respiratory symptoms and diseases, including respiratory allergies, in European countries ${ }^{18}$. Ambrosia is one of the dominant pollen species evoking allergic reactions during late summer and autumn, with a sensitization rate of $26 \%$ in the population of North America and a continuously increasing prevalence of sensitized persons against ragweed in European population ${ }^{19,20}$. There are large variations of sensitization rate against ragweed (2.5-54\%) between European countries and Hungary is the most affected country in Europe ${ }^{21}$.

Published data from Romania confirmed that respiratory allergies, mainly moderate- severe forms of allergic rhinitis, have an increasing prevalence and need rapid diagnostic and therapeutic approach ${ }^{22}$. Ambrosia pollen is a real health problem in many regions of the country, including South and Central regions, not only in the Western part, as considered before $^{23,24}$.

Our actual clinical data from the city of Bucharest showed that the number of patients with sensitization and clinical allergy due to Ambrosia pollen had increased from one year to another during the last three years $(38.46 \%$ increase in two years), mainly the cases with monosensitization and more severe clinical forms. Patients with confirmed clinical allergy to Ambrosia pollen represented 24.21\% from the total number of patients addressed to our department for respiratory symptoms during almost three years. The most frequent clinical form was seasonal rhinitis associated with conjunctivitis and sinusitis, while seasonal allergic asthma was found in only $15.21 \%$ of the cases, but with mostly moderate-severe forms. This rate of asthma is lower than similar data from previous studies evaluating clinical pattern of ragweed -induced allergies ${ }^{25}$. One study showed that association of seasonal conjunctivitis to allergic rhinitis due to ragweed pollen was more frequent in patients from urban area, compared with those from rural ones, possibly due to increased urban pollution ${ }^{26}$. Moderate and severe clinical forms were recorded in almost $80 \%$ of the cases, probably due to hospital presentation during the peak season of Ambrosia pollen in the atmosphere. About one third of the studied group had persistent clinical pattern with seasonal aggravation, despite that no allergologist evaluation had been done before onset of clinical manifestations of allergy to Ambrosia pollen. In these patients with persistent allergy we found sensitization to other perennial or seasonal inhaled allergens, such as dust mites, pets and grass pollen.

Regarding the time from symptoms onset to medical presentation, we noted that only 37 patients from the total 184 were referred to allergologist during the first month of acute respiratory disease and the mean duration since onset of symptoms to medical consultation was 3.2 years. We could not estimate the time from sensitization to ragweed pollen until clinical manifested allergy in our study group, since no allergologist evaluation had been performed before presentation to our hospital. Results of a study over 20-years period performed in northern Italy showed that about 5 years pass between allergic sensitization to ragweed pollen until clinically manifested allergy ${ }^{27}$.

Referring to the risk factors for allergy due to Ambrosia pollen, our study found a significant 
environmental exposure to the invasive plant, which was declared by almost all patients included in the study group and was also confirmed by our pollen monitoring data ${ }^{14,15}$, while history of atopy was found in only $11.95 \%$ of cases. Data from the literature pointed out that the time between exposure to a new allergen in an area until the appearance of allergic sensitization is about $10-15$ years $^{28}$. Since most of the patients included in our study lived in an urban area with high level of atmospheric pollution, we may confirm previous data that urban vegetation from big cities, including Ambrosia, can be dangerous for human health, due to increased aggressiveness of pollen grains associated with other noxious particles $^{29}$. Another recent study performed in Croatia on a group of 4013 children concluded that there were few significant modifying risk factors for sensitization to Ambrosia pollen, except airborne ragweed pollen level in a certain area ${ }^{30}$. Many European countries, including Romania, undertook legal measures in order to stop Ambrosia expansion, but Switzerland is the only country where these measures have been implemented at the beginning of the ragweed invasion and can report still low rates of sensitization and allergies due to ragweed pollen ${ }^{31}$.

\section{Limitation of our study}

The main limitation of our study is the relatively short time and one allergist-limited clinical experience. We have no data about allergic sensitization before clinical allergy onset, since no patient had been investigated before. Longer duration and larger study group from the same area and correlation of clinical evaluation of allergic patients with ragweed pollen monitoring data are needed.

\section{Conclusions}

Our clinical data confirm that respiratory allergies due to Ambrosia pollen represent a serious and increasing public health problem in Bucharest and correlate with our pollen recordings of the last five years, indicating that Ambrosia is an important part of the actual biologic pollution. There is an urgent need for a national strategy to reduce the invasion of Ambrosia in urban environment, to develop national and international research projects for environmental control, disease prevention and promotion of public health.

\section{Compliance with Ethics Requirements:}

"The authors declare no conflict of interest regarding this article"
"The authors declare that all the procedures and experiments of this study respect the ethical standards in the Helsinki Declaration of 1975, as revised in 2008(5), as well as the national law. Informed consent was obtained from all the patients included in the study"

"No funding for this study"

\section{References}

1. Platts-Mills TA. The allergy epidemics: 1870-2010. J Allergy Clin Immunol. 2015;136:3-13.

2. D'Amato G, Cecchi L, Bonini S, et al. Allergenic pollen and pollen allergy in Europe. Review Article. Allergy 2007; DOI: 10.1111/j.1398-9995.

3. Oswald ML, Marshall Jr GD. Ragweed as an Example of Worldwide Allergen Expansion. Allergy, Asthma and Clinical Immunology 2008;4(3):130-135.

4. Wyman M. Autumnal catarrh. Boston Medical Journal 1875;93:209-12.

5. Chen KW, Marusciac L, Tamas PT, Valenta R, Panaitescu C. Ragweed pollen allergy: burden, characteristics, and management of an imported allergen source in Europe. Int Arch Allergy Immunol 2018;176(3-4):163-180.

6. European Commision - Horizon 2020, The EU Framework Program for Research and Innovation. Red alert for ragweed allergy; Available at: https://ec.europa.eu/programmes/horizon2020/en/news/red-alert-ragweed-allergy

7. Hamaoui-Laquel L, Vautard R, Liu L, et al. Effects of climate change and seed dispersal on airborne ragweed pollen loads in Europe. Journal Nature Climate Change. 2015;5:766-771.

8. Ziska LH, Gebhard DE, Frenz DA, Faulkner S, Singer BD, Straka JG. Cities as harbingers of climate change: common ragweed, urbanization and public health. J Allergy Clin Immunol. 2003;111:290-5.

9. Angiola-Crivellaro M, DiBartolomeo D, Genovese A, et al. Air Pollution and Climate Change Task Force of the Italian Society of Allergology, Asthma and Clinical Immunology (SIAAIC). Urban air pollution and climate change: „The Decalogue: Allergy Safe Tree" for allergic and respiratory diseases care. Clin Mol Allergy 2018;16:20.

10. Taramarcaz P, Lambelet C, Clot B, Keimer C, Hauser C. Ragweed (Ambrosia) progression and its health risks: will Switzerland resist this invasion? Swiss Med Wkly 2005;135:538-48.

11. Grewling L, Bogawski P, Kryza M, et al. Concomitant occurrence of anthropogenic air pollutants, mineral dust and fungal spores during long-distance transport of ragweed pollen. Environmental Pollution 2019; 254.

12. Leru PM, Eftimie AM, Anton VF, Thibaudon M. Assessment of the risks associated with the invasive weed Ambrosia artemisiifolia in urban environments in Romania. Ecocycles, 2019;5(1):56-61.

13. Sikoparija B, Skjoth CA, Celenk S, et al. Spatial and temporal variations in airborne Ambrosia pollen in Europe. Aerobiologia 2017;33(2):181-189.

14. Leru PM, Eftimie AM, Thibaudon M. First allergenic pollen monitoring in Bucharest and results of three years collaboration with European aerobiology specialists. Rom J Int Med 2018:56(1):27-33

15. Leru PM, Eftimie AM, Anton VF, Thibaudon M. Five-year data on pollen monitoring, distribution and health impact 
of allergenic plants in Bucharest and the Southeastern region of Romania. Medicina 2019;55:140.

16. Brozek J.L, Bousquet J, Agache I, et al. Allergic rhinitis and its impact on asthma (ARIA) guidelines-2016 revision. J Allergy Clin Immunol. 2017;140:950-958.

17. Global Initiative for Asthma. Global Strategy for Asthma Management and Prevention, 2019. Available from: www. ginasthma.org.

18. Maio S, Baldacci S, Carrozzi L, et al. Respiratory symptoms/ diseases prevalence is still increasing: a $25-\mathrm{yr}$ population study. Respiratory Medicine 2016;10:58-65.

19. Hodgins K. Unearthing the impact of human disturbance on a notorious weed. Mol Ecol 2014;23:2141-3.

20. Bullock JM, Chapman D, Schafer S, et al. Assessing and controlling the spread and the effects of common ragweed in Europe. Final Report ENV.B2/ETU/2010/0037 to the European Commission, DG Environment 2012.

21. Márk Z, Bikov A, Gály G. Characteristics of ragweed allergy in Hungary. Orv Hetil 2016;157:1989-1993.

22. Agache I, Doros IC, Leru PM, Bucur I, Poenaru M, Sarafoleanu C. Real-life effectiveness of a new allergic rhinitis therapy (MP-AzeFlu*) in Romania. Allergy 2016;71(102):386.

23. Florincescu-Gheorghe NA, Popescu F, Alexandru, DO, Popescu, FD. The prevalence of allergic rhinitis to ambrosia elatior in Oltenia area and the association with allergic conjunctivitis or asthma. Curr Health Sci J. 2019;45:66-72.
24. Bocsan IC, Muntean IA, Ureche C, et al. Characterization of patients with allergic rhinitis to Ragweed pollen in two distinct regions of Romania. Medicina 2019;55:712.

25. Buters JTM, Alberternst B, Nawrath S, et al. Ambrosia artemisiifolia (ragweed) in Germany - current presence, allergological relevance and containment prcedures. Allergo J Int 2015;24:108-20.

26. Majkowska-Wojciechowska B, Pełka J, Korzon L, et al. Prevalence of allergy, patterns of allergic sensitization and allergy risk factors in rural and urban children. Allergy 2007;62:1044-1050.

27. Tosi A, Wüthrich B, Bonini M, Pietragalla-Köhler B. Time lag between Ambrosia sensitisation and Ambrosia allergy: A 20-year study (1989-2008) in Legnano, northern Italy. Swiss Med Weekly 2011;141,w13253.

28. Jager S. Ragweed sensitisation rates correlate with the amount of inhaled airborne pollen. A 14-year study in Vienna, Austria. Aerobiologia 2000;16:149-53

29. Ellis AK, Ratz JD, Day AG, Day JH. Factors that affect the allergic rhinitis response to ragweed allergen exposure. Ann Allergy Asthma Immunol 2010;104:293-298.

30. Agnew M, Banic I, Lake IR, et al. Modifiable risk factors for common ragweed (Ambrosia artemisiifolia) allergy and disease in children: a case-control study. Int J Environ Res Public Health 2018;15(7):1339.

31. Ackermann-Liebrich U, Schindler C, Frei P, et al. Sensitization to Ambrosia in Switzerland: a public health threat on the wait. Swiss Med Wkly 2009;139:70-5. 